\title{
Circadian rhythms and clocks in adipose tissues: current insights
}

This article was published in the following Dove Press journal:

ChronoPhysiology and Therapy

4 April 2017

Number of times this article has been viewed

\section{Jana-Thabea Kiehn* \\ Christiane E Koch* \\ Marina Walter \\ Alexandra Brod \\ Henrik Oster}

Chronophysiology Group, Medical Department I, University of Lübeck, Lübeck, Germany

*These authors contributed equally to this work
Correspondence: Henrik Oster Chronophysiology Group, Medical Department I, Center of Brain, Behavior and Metabolism (CBBM), University of Lübeck, Marie Curie Street, DE-23562 Lübeck, Germany

Tel +4945 I 3 I 017836

Fax +49 45I 3101 7845

Email henrik.oster@uni-luebeck.de
Abstract: Endogenous circadian timekeepers are found in most cells and organs of the body, including the different types of adipose tissues. This clock network orchestrates 24-hour rhythms of physiology and behavior to adapt the organism to daily recurring changes in the environment. Energy intake and expenditure as well as adipose physiology are under circadian control and, therefore, energy homeostasis and circadian clock function are closely linked. In this review, we summarize the current knowledge about the regulation and targets of adipocyte circadian clocks and how circadian rhythm disruption affects energy homeostasis and adipose tissue function. We provide a more detailed overview of metabolic phenotypes of different mouse models of circadian clock dysfunction and discuss the implications of (adipose) clock disruption on adipocyte-brain cross talk and metabolic homeostasis.

Keywords: food intake, metaflammation, clock genes, adipocyte-brain cross talk, adipokines

\section{Introduction}

Due to the earth's rotation around its axis, life is embossed by two opposing daily recurring conditions, day and night. To deal with the resulting predictable changes, most species have developed circadian clocks (from Latin circa - about, dies - day) allowing an anticipation of daily recurring events. While a master pacemaker is located in the suprachiasmatic nucleus $(\mathrm{SCN})$ of the hypothalamus, almost all peripheral tissues - including adipose tissues - and many brain nuclei harbor their own functional clocks. ${ }^{1,2}$ The SCN orchestrates these tissue clocks via the endocrine and nervous system to induce rhythmic behavior and physiology (Figure 1).

At the molecular level, circadian clocks are based on interlocked transcriptionaltranslational feedback loops of clock genes/proteins such as the transcription factors Clock (circadian locomotor output cycles kaput) and Bmall (brain and muscle ARNTlike protein 1, also known as Arntl) and the transcriptional modulators Period (Per1-3) and Cryptochrome (Cryl/2). ${ }^{3}$ The oscillation of the circadian clock machinery leads to rhythmic expression of tissue-specific programs of clock-controlled genes (CCGs) through activation of circadian promoter elements (E-boxes, D-boxes, and retinoid orphan response elements, ROREs). In mice, it was estimated that over $40 \%$ of all protein coding genes show circadian oscillations at least in one tissue. ${ }^{4}$ Many of them are involved in metabolic pathways, for example, glucose homeostasis and cholesterol and fatty acid (FA) metabolisms..$^{5}$ Also, several adipokines, which will be discussed in the following text, have been shown to be directly regulated by the circadian clock, for example, leptin and adiponectin. ${ }^{6,7}$ 


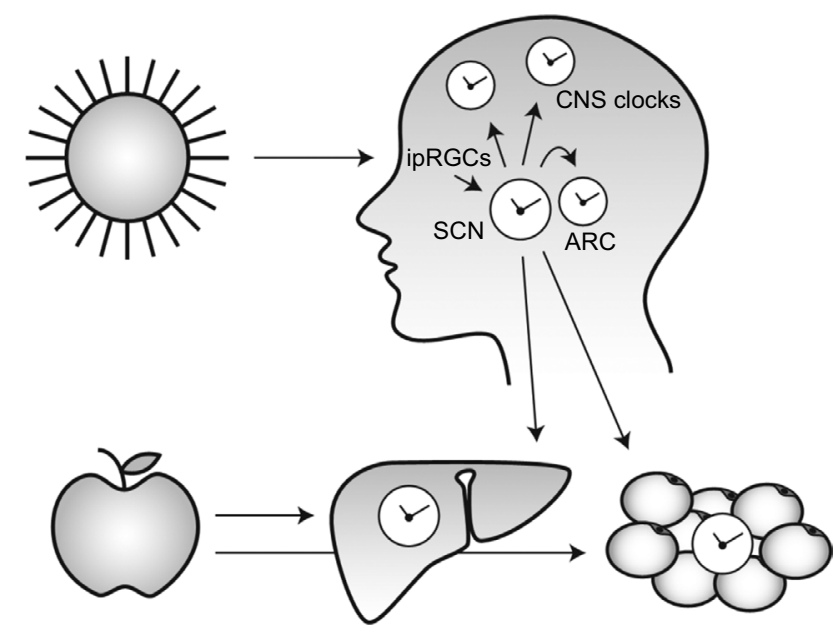

Figure I Different zeitgebers reset the circadian clock network. The circadian master pacemaker in the SCN receives light information via ipRGCs to coordinate peripheral and central subordinate clocks. In this way, behavior and physiological processes are aligned to time-of-day-specific requirements. Peripheral tissue clocks are sensitive to food-mediated signals and adjust to alterations in the diurnal feeding regime. Because food resetting does not affect the $\mathrm{SCN}$, mistimed feeding promotes internal desynchrony.

Abbreviations: ARC, arcuate nucleus; SCN, suprachiasmatic nucleus; ipRGCs, intrinsically photosensitive retinal ganglion cells; CNS, central nervous system.

To generate exact 24-hour rhythms, the circadian system has to be synchronized with the external light-dark cycle. The main synchronizer (or zeitgeber) of mammalian clocks is light. Irradiation information is integrated by intrinsically photosensitive retinal ganglion cells (ipRGCs) and transmitted to the SCN via the retinohypothalamic tract (Figure 1). ${ }^{8-10}$ For peripheral clocks, the timing of food intake is a zeitgeber to align peripheral tissues such as the liver or adipose with energy availability.

Circadian rhythm disruption or genetic alterations in the clock gene machinery lead to pathophysiological effects ranging from sleep disorders to cardiovascular, mental, and metabolic impairments. ${ }^{11-13}$ Since energy homeostasis is centrally regulated, circadian misalignment of the brain-adipose axis might play an important role in the development of metabolic disorders. ${ }^{14,15}$ In this review, we will summarize the current knowledge about adipose clock function with a focus on energy homeostasis.

\section{Adipose tissue circadian clocks}

Like in most cells, circadian clocks are present in adipocytes regulating many essential adipose tissue processes. Lipolysis, adipogenesis, inflammation, brown adipose tissue (BAT) thermogenesis, as well as expression and secretion of several adipose hormones are under circadian control (Figure 2). Circadian rhythm disruptions alter adipose tissue physiology and may affect whole body homeostasis. Hence, adipose clocks are interesting targets for preventing and treating metabolic

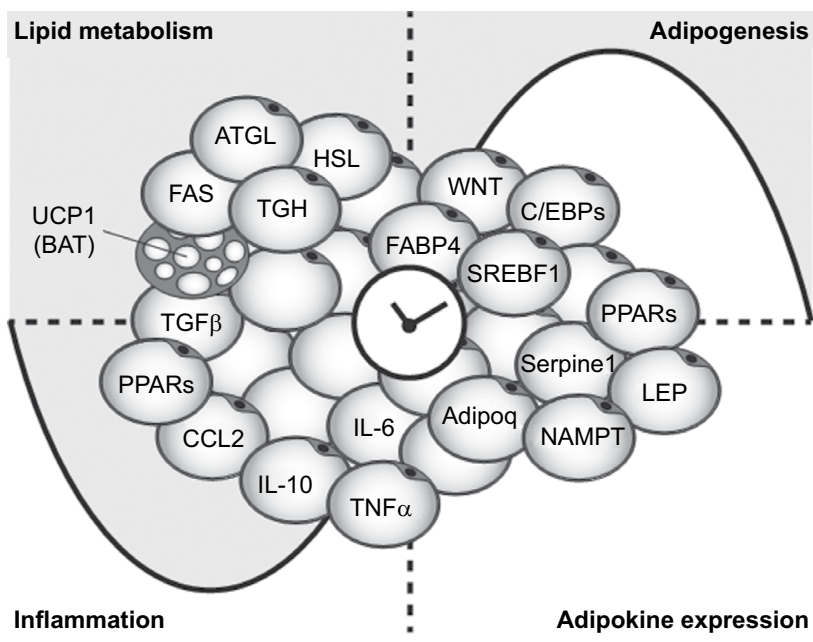

Figure 2 Adipocyte clocks and adipose physiological rhythms. The expression patterns of several adipose genes are under circadian control regulating adipose over the course of the day.

Abbreviations: TGF $\beta$, transforming growth factor beta; $C C L 2, C-C$ motif chemokine ligand; SREBF, sterol regulatory element-binding transcription factor; FABP4, fatty acid-binding protein 4; C/EBP, CCAAT-enhancer-binding protein; IL-10, interleukin-10; TNF $\alpha$, tumor necrosis factor alpha; PPARs, peroxisome proliferator-activated receptors; HSL, hormone-sensitive lipase.

impairments in circadian rhythm disorders, for example, in shift workers.

In vitro and in vivo experiments reveal rhythmic expression of clock genes in different white adipose depots in rodents ${ }^{16-18}$ and humans. ${ }^{19-24}$ In line with this, several hundreds of genes display a diurnal expression rhythm in the adipose tissue of rodent ${ }^{4,17,25,26}$ and human, ${ }^{21}$ some of which are involved in core adipose functions such as lipolysis, adipogenesis, and metabolic inflammation (detailed genes are specified in Figure 2). ${ }^{18,21,25}$

The role of the circadian clock machinery in adipocyte physiology has been described in both in vitro and in animal studies. Knockdown of the clock genes, either Bmall or $R e v-E r b \alpha$, in cells inhibits adipocyte differentiation while mutations of two other clock components, Per 2 or retinoid orphan receptor $\alpha(\mathrm{ROR} \alpha)$, increase adipogenesis. ${ }^{27-32}$ Both effects are mediated by peroxisome proliferator-activated receptor (PPAR $\gamma$ ), a transcription factor crucial for terminal adipocyte differentiation, which is a direct adipose CCG. ${ }^{33,34}$ Interestingly, Bmall seems to have a bimodal impact on adipocyte differentiation. Whereas its knockdown leads to an upregulation of adipogenic genes during early differentiation (by suppression of the canonical Wnt pathway), fewer mature adipocytes survive at later stages. ${ }^{27,35}$ Interestingly, adipose PPAR $\gamma$ (and clock gene) expression rhythms are dampened under high-fat diet (HFD) conditions in male mice. ${ }^{36}$ This effect was not observed in female animals, ${ }^{37}$ in line with a persistent normal diurnal food intake 
rhythm, which usually breaks down under HFD conditions in male mice. ${ }^{36,38-40}$ This example highlights the complex interaction of cellular adipose clocks with external signals (e.g., food composition and gender effects) in adipocyte differentiation.

Different aspects of lipid metabolism in white adipose tissue (WAT) and BAT are controlled by the circadian clock, including lipolysis, lipogenesis, and BAT thermogenesis. ${ }^{41,42}$ This makes sense if one considers that these processes have to be timely regulated due to diurnal changes in systemic energy demands. Baseline lipolysis rates are elevated during the rest phase of the animal. ${ }^{43}$ This circadian rhythm persists ex vivo. In isolated adipocytes, adrenaline-induced lipolysis exhibits diurnal differences. ${ }^{44}$ Shostak et $\mathrm{al}^{18}$ have shown that, in mice, lipolysis is controlled by CLOCK:BMAL1mediated expression of Atgl (adipose triglyceride lipase) and $H s l$ (hormone-sensitive lipase), encoding for two ratelimiting lipolytic enzymes. Furthermore, expression of some enzymes regulating FA uptake and activation shows diurnal oscillation in murine WAT with a maximum in the early dark phase. ${ }^{43}$ This is in line with increased lipogenesis during the active phase. Consistently, plasma triglycerides, free fatty acid (FFA), and cholesterol concentrations display diurnal oscillations that even persist during fasting. ${ }^{25,45-47}$ Constant routine studies suggest that these self-sustained rhythms are preserved in humans. ${ }^{45}$ Interestingly, the products of lipid breakdown (i.e., glycerol and FA) make up over 75\% of all rhythmic metabolites in the blood peaking in the late morning. ${ }^{45}$ An important mediator of circadian clock regulation of lipid metabolism is PPAR $\alpha,{ }^{48-50}$ a nuclear receptor involved in transport, activation, and storage of FA as well as BAT thermogenesis. ${ }^{51}$ BAT PPAR $\alpha$ induces UCPI (uncoupling protein) expression which is essential for non-shivering thermogenesis. Since Per 2 acts as coactivator for PPAR $\alpha$-mediated Ucp 1 expression and simultaneously promotes BAT expression of Fabp3 (fatty acid-binding protein) which enhances the UCP 1 activity, thermogenesis displays a circadian pattern. Deletion of Per 2 results in a cold-sensitive phenotype. ${ }^{52}$ Furthermore, isolated brown adipocytes lacking $R e v-E r b \alpha$ show elevated $U c p 1$ expression which is normalized by overexpressing Rev-Erb $\alpha$ in these adipocytes. In line, during the active phase, wild-type mice show a reduced thermoregulatory capacity associated with high expression of Rev-Erb $\alpha$ in BAT. Deletion of Rev-Erb $\alpha$ leads to a time-of-day independent thermoregulation. ${ }^{53}$ As a consequence, circadian disruptions are often associated with impaired lipolysis and thermogenesis resulting in obesity (discussed in the following sections). ${ }^{18}$

\section{Adipose function in clock gene- mutant mice}

Many clock gene-mutant mouse strains show changes in adipose physiology (Table 1) often associated with altered body weight. Clock- $\Delta 19$ mutants show increased body weight and fat content with adipocyte hypertrophy. ${ }^{18,38,54,55}$ Furthermore, these mice are hyperphagic and display a dampened feeding rhythm. ${ }^{18,38}$ In Clock- $\Delta 19$, WAT expression of Atgl and $H s l$ is arrhythmic and overall low, and mice show lower lipolytic responses during fasting. Because of a decreased lipid utilization, blood glycerol and FFA concentrations are reduced. ${ }^{42}$ On the other hand, Clock- $\Delta 19$ mice show elevated circulating cholesterol and triglyceride levels, ${ }^{38,56,57}$ likely due to hepatic overproduction and elevated intestinal absorption. ${ }^{56,57}$ Of note, the metabolic consequences of this Clock mutation depend on the genetic background. While most experiments were performed in the original $\mathrm{C} 57 \mathrm{BL} / 6 \mathrm{~J}$ background, Clock- $\Delta 19$ mice on a (melatonin-proficient) CBA background show normal body weight and fat content. ${ }^{58-60}$ Clock mutants on an ICR background also show increased food intake, but body weight is even lower than in wild-type littermates - a consequence of impaired lipid absorption. ${ }^{48,61}$

Mice with mutations in the gene encoding the CLOCK partner protein BMAL1 show less ambiguous phenotypes with elevated adiposity, despite unaffected food intake. ${ }^{7,35,62-67}$ This could be explained by the WNT-mediated suppressive effect of Bmall on adipogenesis. ${ }^{35}$ However, since Bmall knockout (KO) mice show an early aging phenotype, the adipose phenotype can only be observed in young animals. ${ }^{66}$

Genetic deletions in the negative limb of the circadian feedback loop provide varying results with regard to appetite and body weight control. While Cry double-mutant mice show dampened feeding rhythms on normal chow diet (NCD) and HFD, they are generally lighter and leaner than wild-type controls. ${ }^{7,40,68}$ Under HFD, however, they rapidly gain weight despite a lower food intake compared to wild types. ${ }^{40}$ This effect is explained by an enhanced potential of Cry-mutant adipocytes for lipid uptake and insulin-stimulated lipogenesis, making them highly susceptible to HFD-induced obesity.

Per1- and Per2-mutant mice on the same genetic background show an opposite body weight phenotype. Whereas Per $1^{m / m}$ mice show reduced body weight, a mutation of Per2 (Per ${ }^{m / m}$ mice) results in elevated body weight. ${ }^{69,70}$ Despite different body weight effects, food intake is increased in both strains suggesting a higher metabolic rate in Perl mutants. ${ }^{69}$ $P e r 3^{-/-}$mice on NCD show increased body weight. ${ }^{71}$ On HFD, all Per mutants display elevated body weight and fat mass without an increase in absolute food intake suggesting 
Table I Overview of adipose tissue phenotypes of clock gene-mutant mice

\begin{tabular}{|c|c|c|c|c|c|c|}
\hline $\begin{array}{l}\text { Clock } \\
\text { genes }\end{array}$ & Body weight & Adipose tissue & Food intake & Blood lipids & Adipokines & References \\
\hline Bmall & $\begin{array}{l}\downarrow / \uparrow \text { on NC (age } \\
\text { effect) } \\
\leftrightarrow / \uparrow \text { on HFD }\end{array}$ & $\begin{array}{l}\uparrow \text { adiposity on } \\
\mathrm{NC} \text { and HFD }\end{array}$ & $\begin{array}{l}\leftrightarrow \text { on } \mathrm{NC} \text { and } \\
\mathrm{HFD}\end{array}$ & $\begin{array}{l}\uparrow \text { TGs (n.r.) } \\
\uparrow \text { cholesterol and NEFAs } \\
\text { on HFD } \\
\downarrow \text { FAAs and glycerol (n.r.) }\end{array}$ & $\begin{array}{l}\uparrow \text { leptin, adiponectin, } \\
\text { PAl-I }\end{array}$ & $7,35,40,62,63,65,109$ \\
\hline $\begin{array}{l}\text { Clock } \\
(C 57 B L / 6)\end{array}$ & $\uparrow$ on NC \& HFD & $\uparrow$ adiposity & $\begin{array}{l}\uparrow \text { on } \mathrm{NC} \text { and } \\
\text { HFD dampened } \\
\text { rhythm }\end{array}$ & $\begin{array}{l}\uparrow \text { TGs and cholesterol } \\
\downarrow \text { FFAs and glycerol (n.r.) }\end{array}$ & $\uparrow$ leptin & 38,42 \\
\hline Clock (CBA) & $\begin{array}{l}\leftrightarrow \text { on NC } \\
\downarrow \text { on HFD }\end{array}$ & $\leftrightarrow$ adiposity & & $\downarrow$ FFAs on NC and HFD & $\begin{array}{l}\uparrow \text { adiponectin on NC } \\
\leftrightarrow \text { leptin on NC } \\
\leftrightarrow \text { adiponectin on HFD } \\
\downarrow \text { leptin on HFD }\end{array}$ & 59,60 \\
\hline Clock (ICR) & $\begin{array}{l}\leftrightarrow \text { on } \mathrm{NC} \\
\leftrightarrow / \downarrow \text { on HFD }\end{array}$ & & $\begin{array}{l}\leftrightarrow \text { on } \mathrm{NC} \text { and } \\
\mathrm{HFD}\end{array}$ & $\begin{array}{l}\leftrightarrow / \downarrow \text { TGs and FFAs on } \\
\mathrm{NC} \\
\leftrightarrow \text { TGs on HFD } \\
\uparrow \text { FFAs on HFD }\end{array}$ & $\begin{array}{l}\leftrightarrow \text { leptin on NC and } \\
\text { HFD }\end{array}$ & 61 \\
\hline Cryl/2 & $\begin{array}{l}\downarrow \text { on } \mathrm{NC} \text { and } \\
\text { HFD }\end{array}$ & $\begin{array}{l}\downarrow \text { adiposity on NC } \\
\uparrow \text { adiposity on } \\
\text { HFD }\end{array}$ & $\begin{array}{l}\leftrightarrow \text { on NC } \\
\downarrow \text { on HFD } \\
\text { dampened } \\
\text { rhythm }\end{array}$ & $\begin{array}{l}\leftrightarrow \text { TGs, cholesterol and } \\
\text { FFAs on HFD }\end{array}$ & $\begin{array}{l}\downarrow \text { leptin on NC } \\
\leftrightarrow \text { leptin on HFD }\end{array}$ & $\begin{array}{l}40,68 \\
69\end{array}$ \\
\hline Perl & $\downarrow$ on NC & & $\begin{array}{l}\uparrow \text { on NC (relative } \\
\text { to body weight) }\end{array}$ & & & 70 \\
\hline Per2 & $\begin{array}{l}\uparrow \text { on NC } \\
\uparrow \text { on HFD }\end{array}$ & $\begin{array}{l}\uparrow \text { adiposity on } \\
\text { HFD }\end{array}$ & $\begin{array}{l}\leftrightarrow / \uparrow \text { on NC } \\
\uparrow \text { on HFD } \\
\text { dampened } \\
\text { rhythm }\end{array}$ & & & 70,72 \\
\hline Per3 & $\begin{array}{l}\leftrightarrow \text { on NC } \\
\uparrow \text { on HFD }\end{array}$ & $\begin{array}{l}\uparrow \text { adiposity on NC } \\
\text { and HFD }\end{array}$ & $\begin{array}{l}\leftrightarrow \text { on chow and } \\
\text { HFD }\end{array}$ & & & 73 \\
\hline Perl/2 & $\uparrow$ on NC & $\uparrow$ adiposity & $\begin{array}{l}\leftrightarrow \text { on chow } \\
\text { dampened } \\
\text { rhythm }\end{array}$ & & $\uparrow$ leptin (n.r.) & 74 \\
\hline Perl-3 & $\uparrow$ on HFD & $\begin{array}{l}\uparrow \text { adiposity on } \\
\text { HFD }\end{array}$ & $\begin{array}{l}\uparrow \text { on chow (rel. } \\
\text { to BW) and HFD }\end{array}$ & & & 72 \\
\hline RevErbo & $\begin{array}{l}\leftrightarrow / \uparrow \text { on } \mathrm{NC} \\
\uparrow \text { on } \mathrm{HFD}\end{array}$ & $\begin{array}{l}\uparrow \text { adiposity on NC } \\
\text { and HFD }\end{array}$ & $\leftrightarrow$ on chow & $\begin{array}{l}\downarrow \text { TGs and glycerol on } \\
\text { HFD } \\
\uparrow \text { LDL, cholesterol and } \\
\text { NEFAs on HFD }\end{array}$ & $\begin{array}{l}\uparrow \text { leptin \& adiponectin } \\
\text { on NC \& HFD }\end{array}$ & 72,73 \\
\hline$R O R \alpha$ & $\begin{array}{l}\downarrow \text { on } \mathrm{NC} \text { and } \\
\text { HFD }\end{array}$ & $\begin{array}{l}\downarrow \text { adiposity on NC } \\
\text { and HFD }\end{array}$ & $\uparrow$ on HFD & $\begin{array}{l}\downarrow \text { cholesterol, HDL, and } \\
\text { NEFAs } \\
\downarrow \text { FFAs on HFD }\end{array}$ & $\downarrow$ leptin mRNA in WAT & 32,76 \\
\hline
\end{tabular}

Note: Arrows indicate increased $(\uparrow)$, unaltered $(\leftrightarrow)$, and decreased $(\downarrow)$ levels compared to controls.

Abbreviations: n.r, not rhythmic; NC, normal chow; HFD, high-fat diet; FFA, free fatty acid; NEFA, non-esterified fatty acid; TG, triglyceride; BW, body weight; L/HDL, low-/high-density lipoprotein.

alterations in energy efficiency. ${ }^{72}$ Body weight and fat content of clock-deficient Per1/Per2 double mutants are elevated, indicating a dominant effect of Per2 mutation on energy metabolism. ${ }^{7}$ Food intake and body weight of Per1/Per2/ Per3 triple mutants are elevated during HFD. In summary, Per mutations in mice mostly lead to adiposity, in line with effects seen in adipocytes in vitro. ${ }^{28}$

Mice carrying mutations in genes involved in accessory loops of the clock machinery also show metabolic alterations. Mice with genetic deletion of the nuclear orphan receptor Rev-Erb $\alpha$ (Nrldl) show normal to slightly increased body weight on NCD and an elevated body weight on HFD. ${ }^{73,74}$ Body fat percentage is increased on both diets. Consistently, treatment of obese wild-type mice with a synthetic REV$E R B \alpha$ agonist reduces the obese phenotype due to increased energy expenditure and decreased expression of lipogenic genes. ${ }^{75}$ Opposite effects are seen if an activator of Bmall expression, Ror $\alpha$, is mutated. Body weight, fat mass, and adipocytes of staggerer mice (carrying a Ror $\alpha$ loss-of-function mutation) are reduced independent of diet conditions..$^{32,76}$ Although food intake of staggerer mice is elevated on HFD compared to controls, they do not show typical HFD-induced 
obesity. ${ }^{76}$ This is associated with decreased expression of lipogenic genes (e.g., sterol regulatory element-binding protein $[$ Srebp-1c] and FA synthase [Fas]) and increased expression of genes regulating oxidative metabolism (e.g., PPAR $\gamma$ coactivator $1[$ Pgc-1 $\alpha / \beta]$ and lipin 1$)$.

\section{Adipocyte-specific clock disruption}

A frequent problem in interpreting the phenotypes of clock gene-mutant mice is the difficulty to pinpoint which tissue clock determines the effect. This is particularly true for WAT, which is heavily influenced by systemic factors such as hormones and metabolic state. Therefore, although most clock gene mutants show alterations in adipose function, it cannot be excluded that these originate from outside the WAT. To study the specific role of the adipocyte clock itself, mouse models with $\mathrm{CRE} /$ lox $P$-driven deletion of the essential clock component Bmall have been developed. ${ }^{77}$ Comparable to conventional Bmall KO mice, animals carrying an aP2-Cre-driven deletion of Bmall primarily targeting WAT show hyperphagy and increased obesity independent of the type of diet. In line with this, they display increased serum leptin levels with dampened diurnal rhythmicity.,77 In contrast, mice in which Bmall deletion is mediated by another adipose-targeting CRE driver, Adipoq (adiponectin), show a much milder phenotype with normal body weight on NCD, but an increased vulnerability to the obesogenic effects of HFD. ${ }^{77}$ In aP2-Cre $\times$ Bmall-flox mice, the mechanisms of this change in metabolic state have been further characterized. Mutant mice show a lower concentration of polyunsaturated fatty acids (PUFAs) in WAT and plasma due to lower expression of the lipolytic gene Ces1d (carboxylesterase 1d) at CT4 and of Elovl6 (elongation of long-chain fatty acids) and Scdl (stearoyl-coenzyme A desaturase 1), which catalyze the biosynthesis of long-chain PUFAs. All these genes contain circadian E-box regulatory elements in their promoter regions. PUFAs can cross the blood-brain barrier and inhibit appetite. ${ }^{78,79}$ The lower PUFA levels in aP2-Cre $\times$ Bmall-flox mice could, therefore, explain the observed hyperphagy and elevated body weight. Indeed, aP2-Cre $\times$ Bmall-flox mice fed with a PUFA-rich diet show wild-type-like food intake and body weight gain, energy expenditure, and normalized circadian expression of orexigenic and anorexigenic neuropeptides in the hypothalamus. ${ }^{77}$ Of note, ectopic activity of the $a P 2$ driver has been reported in several tissues including the brain. ${ }^{80}$ Therefore, it will be important to investigate if these physiological changes are also observed in other adipose-specific clock mutants such as Adipoq-Cre $\times$ Bmall-flox mice.

\section{The role of SCN pacemaker in adipose rhythms}

As mentioned earlier, signals derived from other tissues and, thus, clocks in other tissues - may impinge on adipose rhythms. Of particular interest in this context is the SCN pacemaker itself as coordinator of all endogenous clocks and rhythms. Lesions of the SCN lead to arrhythmic locomotor activity, drinking behavior, and serum leptin levels. ${ }^{81,82}$ This dampened rhythm in oscillating leptin seems to be a direct effect of the SCN lesion and not of altered food intake since regularly scheduled meals have no effect on the rhythm of leptin. ${ }^{82}$ However, lesions of the SCN do not just affect the clock in the SCN but also destroy the SCN neuronal structure that serves as a relay of external light information to peripheral clocks. ${ }^{83}$ To bypass this issue, mouse models with (more or less) tissue-specific genetic deletion of SCN clock function have been developed. ${ }^{26,84,85}$ While under light-dark (LD) conditions peripheral clock gene and behavioral rhythms are preserved in SCN Bmal1-KO mice, they become in constant darkness behaviorally arrhythmic while peripheral clocks and hormone rhythms only gradually desynchronize and, thus, continue to cycle for some days. ${ }^{85}$ Microarray studies in WAT of these mice reveal that many adipose transcripts associated with lipid and carbohydrate metabolism lose their rhythm suggesting a dependence on SCN clock-driven rhythmic behavior independent of adipocyte clock function. ${ }^{26}$ Interestingly, expression of some immune genes gains rhythmicity in the absence of a functional SCN clock. This may indicate a counteractive regulation of cellular immunity by SCN and adipocyte clocks. ${ }^{26}$

\section{Modulation of adipose rhythms by food}

The daily rhythm of food intake has a strong influence on metabolic homeostasis, ${ }^{86-88}$ which may in part be mediated by its synchronizing effects on peripheral clock function (Figure 1). ${ }^{89}$ Most studies investigating peripheral clock gene entrainment so far have focused on the liver, and the data for food resetting of adipose clocks are limited.

Nocturnal rodents, like mice and rats, with restricted access to food during the light phase - their normal rest phase - gain more weight than littermates with dark phaserestricted food intake. ${ }^{90,91}$ This effect does not concur with increased total food intake and it seems that the mistiming of food intake is the key to this maladaptation. Rest-phase feeding leads to higher lipogenic gene expression, abolishes the rhythm in lipolytic gene expression, and alters rhythms of circulating leptin and insulin, energy metabolism, and body 
temperature. ${ }^{91-93}$ On the other hand, nighttime-restricted feeding leads to lower serum leptin, higher BAT thermogenesis, and lower WAT expression of pro-inflammatory cytokines. ${ }^{94}$ To which extent these adipose effects are direct consequences of alterations in energy supply or follow food-mediated resetting of adipocyte clocks remains to be explored.

\section{Adipokine rhythms}

WAT is a very active endocrine tissue. Depending on energy state, adipocytes secrete a large array of different peptides, the so-called adipokines, several of which show diurnal expression patterns. ${ }^{16,95}$ Besides peripheral targets, many adipokines enter the brain where they modulate central regulatory circuits of appetite control and energy expenditure, thus providing bottom-up feedback about the peripheral energy state of the body to ensure homeostasis (Figure 3). Disruption of this adipocyte-brain cross talk is associated with a broad range of mental and metabolic impairments. ${ }^{96-100}$ In obese humans, altered adipose clock gene expression is associated with metabolic impairments. ${ }^{101}$ In line, deleting the clock specifically in adipose tissue affects hypothalamic gene expression of appetite-regulating neuropeptides resulting in a dampened feeding rhythm. ${ }^{77}$ These central alterations due to circadian disruptions in the WAT might be, at least partially, mediated by modulated adipokine secretion.

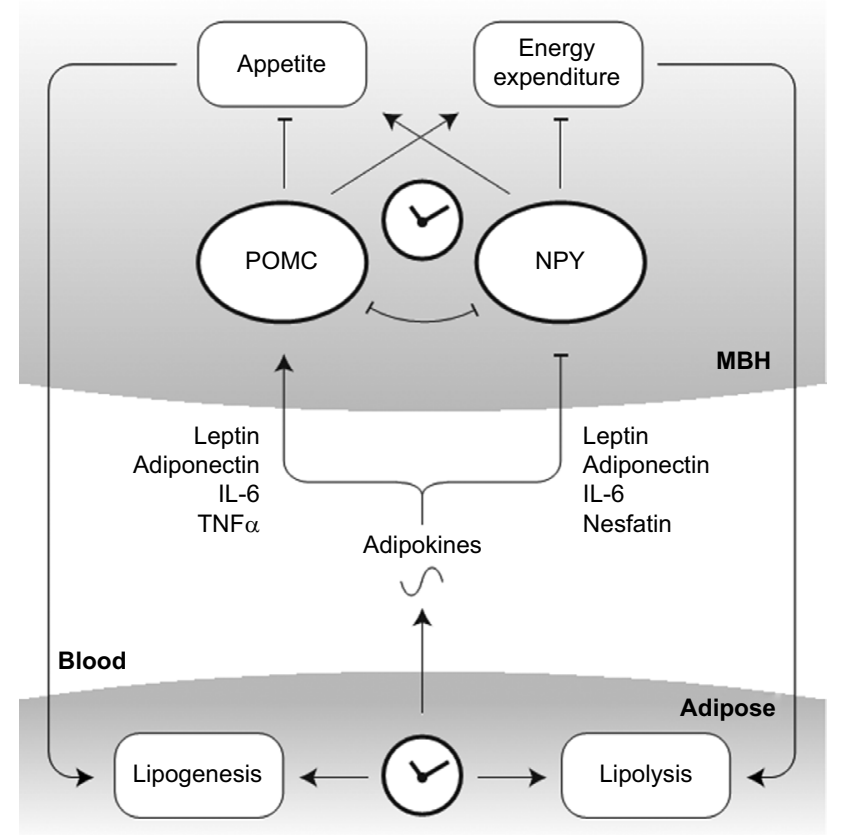

Figure 3 Adipose-brain cross talk in the regulation of energy homeostasis. Rhythmically regulated adipokines cross the blood-brain barrier to affect appetiteand energy expenditure-regulating circuits in the mediobasal hypothalamus (MBH). In turn, altered energy intake and demands remodulate adipose function along the day. Abbreviations: POMC, pro-opiomelanocortin; NPY, neuropeptide Y; IL-6, interleukin 6; TNF $\alpha$, tumor necrosis factor alpha.
The mRNA of leptin, the most prominent adipokine, is rhythmically expressed in adipocytes, ${ }^{16,102}$ and its circulating concentration rises during the night in humans ${ }^{103,104}$ and nocturnal rodents. ${ }^{7,82,105,106}$ In obesity, leptin serum concentrations are increased in mice and humans, while oscillations are dampened, ${ }^{103,104}$ probably due to the concomitant dampened feeding rhythm. ${ }^{36,38-40}$ Kettner et $\mathrm{al}^{7}$ showed rhythmic binding of BMAL1 to E-boxes in the Lep promoter that modulate C/ EBP $\alpha$-controlled Lep transcription in a daytime-dependent manner. The rhythmicity of leptin seems to be critical for energy homeostasis. Leptin-deficient (ob/ob) mice treated with leptin in anti-phase to their food intake rhythm gain more weight than mice treated in line with the feeding rhythm. ${ }^{93}$

Other adipokines such as adiponectin also show diurnal oscillations. Adipoq mRNA expression in WAT and adiponectin blood concentrations peak during the active phase of mice and humans. ${ }^{6,16,107-110}$ Like leptin, adiponectin serum concentrations display dampened circadian and ultradian oscillations in obese subjects. ${ }^{107,109}$ The Adipoq promoter contains several E-box-like sequences and can be activated by CLOCK:BMAL. ${ }^{6,111}$ Interestingly, overexpression of human adiponectin in the liver of KK/Ta mice, which have low endogenous adiponectin levels, partly restores the circadian rhythm and free-running period of locomotor activity, indicating a role of adiponectin in central behavior regulation. ${ }^{112}$ Gene expression of this insulin-sensitizing adipokine is modulated by food intake; thus, its circadian action could be important for the circadian regulation of insulin sensitivity. ${ }^{62,113}$

Some of the other adipokines that show diurnal expression rhythms are resistin, visfatin (nicotinamide phosphoribosyltransferase, Nampt), plasminogen activator inhibitor-1 (Serpine1, PAI-1), TNF $\alpha$ (tumor necrosis factor alpha), and IL-6 (interleukin-6). Expression of PAI-1 and visfatin is known to be directly controlled by the circadian clock. ${ }^{114-121}$ Additionally, visfatin can feed back on the circadian clock via the NAD+ salvage pathway. ${ }^{119,120}$ In murine WAT, mRNA expression of resistin and visfatin peaks during the dark phase, ${ }^{16,120,122}$ while mRNA expression of PAI-1 is highest during the light phase. ${ }^{114}$ Activity of plasma PAI-1, however, is highest at the beginning of the active phase. ${ }^{114,123,124} \mathrm{TNF} \alpha$ peaks in serum of lean rats during the inactive phase. ${ }^{125,126}$ Interestingly, if mice are fed a HFD, the peak of serum TNF $\alpha$ shifts to the active phase. ${ }^{125}$ IL-6 shows rhythmic gene expression in human subcutaneous WAT. ${ }^{21}$ Furthermore, diurnal oscillations of serum IL-6 are well documented in humans, ${ }^{127,128}$ but the situation is less clear in rodents. ${ }^{125,126,95}$ To which extent these adipose-derived cytokine oscillations contribute to metabolic inflammatory processes (see the following text) remains to be explored. 
It should be noted that even in the absence of rhythmic hormone concentrations time-of-day-dependent effects can be achieved in target tissues. For example, leptin transport into the brain and the mRNA expression of its receptor, LepR (or $O b R$ ), show diurnal rhythmicity in the hypothalamus. ${ }^{129,130}$ This could indicate circadian rhythms in the central sensitivity to leptin and interpretation of the leptin signal (circadian gating). Indeed, destruction of LepR-expressing neurons in the arcuate nucleus leads to dampened feeding rhythms and to arrhythmicity of locomotor activity in DD. ${ }^{131}$ Interestingly, LepR is also expressed in the SCN of humans and rodents indicating a possible direct effect of leptin on the central pacemaker ${ }^{132-134}$ (note the reported absence of LepR in the SCN reported by Caron et al ${ }^{135}$ ).

\section{Circadian rhythms and metaflammation}

Metaflammation (short for metabolic inflammation) depicts a low-grade chronic inflammatory state resulting from overnutrition and playing a crucial role in the development of obesity-associated insulin and leptin resistance and cardiovascular complications. ${ }^{136}$ Metaflammation originates from WAT, but later spreads to other peripheral tissues such as liver, skeletal muscle, pancreatic islets, and the hypothalamus. ${ }^{136,137}$

Under obese conditions, the number of WAT infiltrating macrophages releasing pro-inflammatory cytokines (M1 macrophages) increases. ${ }^{138}$ Furthermore, pro-inflammatory cytokine production is enhanced by elevated activation of pro-inflammatory kinases like c-Jun N-terminal kinase, inhibitor of $\mathrm{\kappa B}$ kinase, and protein kinase $\mathrm{R}$ and their signaling cascades. ${ }^{139,140}$ Additionally, the inflammasome and toll-like receptors, components of the innate immune system, are activated during metaflammation. ${ }^{141-143}$ The triggers and mechanisms of metaflammation are still poorly understood, but it has been noted that in obesity, feeding rhythms are dampened leading to an uninterrupted inflammatory stimulus. ${ }^{136}$ In a similar way, exposure to dim light during the dark phase influences clock gene expression in WAT and activates the expression of pro-inflammatory cytokines (macrophage-1 antigen, TNF $\alpha){ }^{144,145}$ Time-restricted HFD access, on the other hand, has been shown to not just improve diurnal oscillations of clock gene expression but also to prevent increased macrophage infiltration and increased cytokine production in WAT. ${ }^{146}$

Circadian clock KO mice seem to be more susceptible for pro-inflammatory stimulus. LPS treatment of bone marrowderived macrophages leads to a higher induction of TNF $\alpha$ and IL-1 $\beta$ expression in Per-mutant mice. ${ }^{147}$ Furthermore, Permutant mice show a higher percentage of M1 macrophages in
WAT. HFD-fed mice with myeloid-specific disruption of Per $1 / 2$ display elevated gene expression of TNF $\alpha$, IL-6, and IL-1 $\beta$ and increased macrophage infiltration in WAT. This seems to be mediated by PPAR $\gamma$, which is downregulated in Perl/2mutant mice. Myeloid-specific deletion of Bmall results in elevated numbers of inflammatory monocytes in WAT and BAT, increased body weight gain, and impaired glucose tolerance. ${ }^{148}$ It will be interesting to follow up this clock-inflammation lead as a potential target for the treatment of metaflammation.

\section{Conclusion}

Many important adipose functions including adipose differentiation, lipid metabolism, and adipokine expression are controlled by the adipocyte circadian clock or systemic factors such as food intake and SCN-dependent hormones. Vice versa adipose-derived factors, the adipokines, can modulate circadian appetite and energy metabolism rhythms in the brain. Circadian rhythm disruption, thus, has double effects on energy homeostasis; it affects WAT function via resetting of adipocyte clocks and alters central metabolic regulation directly and through modulation of adipokine signaling. This circadian aspect of the adipocyte-brain cross talk may have an important role in the regulation of obesity-associated metaflammation.

Considering the rising numbers of patients with metabolic disorders, targeting the circadian clock system may be a promising preventive and therapeutic approach. ${ }^{41,149,150}$ In particular, those adipokines that do not lose their central anorexigenic properties during obesity, like nesfatin or adiponectin, may have chronotherapeutic potential. ${ }^{151}$ Other approaches may affect clock proteins directly such as the nuclear orphan receptor $R E V-E R B \alpha$ for which small molecule modulators have already been developed. ${ }^{75}$

\section{Author contributions}

All authors contributed toward data analysis, drafting and revising the paper and agree to be accountable for all aspects of the work.

\section{Disclosure}

HO is a Lichtenberg Fellow of the Volkswagen Foundation. CEK was funded in part by a CRC grant of the Deutsche Forschungsgemeinschaft (DFG; TR-SFB134). JTK was funded by a GRK grant of the DFG (GRK1957). The authors report no other conflicts of interest in this work.

\section{References}

1. Ralph MR, Foster RG, Davis FC, Menaker M. Transplanted suprachiasmatic nucleus determines circadian period. Science. 1990;247(4945): 975-978. 
2. Guilding C, Hughes AT, Brown TM, Namvar S, Piggins HD. A riot of rhythms: neuronal and glial circadian oscillators in the mediobasal hypothalamus. Mol Brain. 2009;2:28.

3. Buhr ED, Takahashi JS. Molecular components of the Mammalian circadian clock. Handb Exp Pharmacol. 2013;217:3-27.

4. Zhang R, Lahens NF, Ballance HI, Hughes ME, Hogenesch JB. A circadian gene expression atlas in mammals: implications for biology and medicine. Proc Natl Acad Sci U SA. 2014;111(45):16219-16224.

5. Panda S, Antoch MP, Miller BH, et al. Coordinated transcription of key pathways in the mouse by the circadian clock. Cell.2002;109(3):307-320.

6. Barnea M, Chapnik N, Genzer Y, Froy O. The circadian clock machinery controls adiponectin expression. Mol Cell Endocrinol. 2015; 399:284-287.

7. Kettner NM, Mayo SA, Hua J, Lee C, Moore DD, Fu L. Circadian dysfunction induces leptin resistance in mice. Cell Metab. 2015;22(3):448-459.

8. Freedman MS, Lucas RJ, Soni B, et al. Regulation of mammalian circadian behavior by non-rod, non-cone, ocular photoreceptors. Science. 1999;284(5413):502-504.

9. Hattar S, Liao HW, Takao M, Berson DM, Yau KW. Melanopsincontaining retinal ganglion cells: architecture, projections, and intrinsic photosensitivity. Science. 2002;295(5557):1065-1070.

10. Moore RY, Lenn NJ. A retinohypothalamic projection in the rat. J Comp Neurol. 1972;146(1):1-14.

11. Valenzuela FJ, Vera J, Venegas C, et al. Evidences of polymorphism associated with circadian system and risk of pathologies: a review of the literature. Int J Endocrinol. 2016;2016:2746909.

12. Dibner C, Schibler U. Circadian timing of metabolism in animal models and humans. J Intern Med. 2015;277(5):513-527.

13. Bechtold DA, Gibbs JE, Loudon AS. Circadian dysfunction in disease. Trends Pharmacol Sci. 2010;31(5):191-198.

14. Challet E. Keeping circadian time with hormones. Diabetes Obes Metab. 2015;17(Suppl 1):76-83.

15. Tsang AH, Barclay JL, Oster H. Interactions between endocrine and circadian systems. J Mol Endocrinol. 2013;52(1):R1-R16.

16. Ando H, Yanagihara H, Hayashi Y, et al. Rhythmic messenger ribonucleic acid expression of clock genes and adipocytokines in mouse visceral adipose tissue. Endocrinology. 2005;146(12):5631-5636.

17. Zvonic S, Ptitsyn AA, Conrad SA, et al. Characterization of peripheral circadian clocks in adipose tissues. Diabetes. 2006;55(4):962-970.

18. Shostak A, Meyer-Kovac J, Oster H. Circadian regulation of lipid mobilization in white adipose tissues. Diabetes. 2013;62(7):2195-2203.

19. Wu X, Zvonic S, Floyd ZE, et al. Induction of circadian gene expression in human subcutaneous adipose-derived stem cells. Obesity (Silver Spring). 2007;15(11):2560-2570.

20. Huang TS, Grodeland G, Sleire L, Wang MY, Kvalheim G, Laerum OD. Induction of circadian rhythm in cultured human mesenchymal stem cells by serum shock and cAMP analogs in vitro. Chronobiol Int. 2009;26(2):242-257.

21. Loboda A, Kraft WK, Fine B, et al. Diurnal variation of the human adipose transcriptome and the link to metabolic disease. BMC Med Genomics. 2009;2:7.

22. Gómez-Santos C, Gómez-Abellán P, Madrid JA, et al. Circadian rhythm of clock genes in human adipose explants. Obesity (Silver Spring). 2009;17(8):1481-1485.

23. Garaulet M, Ordovás JM, Gómez-Abellán P, Martínez JA, Madrid JA. An approximation to the temporal order in endogenous circadian rhythms of genes implicated in human adipose tissue metabolism. J Cell Physiol. 2011;226(8):2075-2080.

24. Otway DT, Mäntele S, Bretschneider S, et al. Rhythmic diurnal gene expression in human adipose tissue from individuals who are lean, overweight, and type 2 diabetic. Diabetes. 2011;60(5):1577-1581.

25. Sukumaran S, Xue B, Jusko WJ, Dubois DC, Almon RR. Circadian variations in gene expression in rat abdominal adipose tissue and relationship to physiology. Physiol Genomics. 2010;42A(2): 141-152.

26. Kolbe I, Husse J, Salinas G, Lingner T, Astiz M, Oster H. The SCN clock governs circadian transcription rhythms in murine epididymal white adipose tissue. J Biol Rhythms. 2016;31(6):577-587.
27. Shimba S, Ishii N, Ohta $\mathrm{Y}$, et al. Brain and muscle Arnt-like protein-1 (BMAL1), a component of the molecular clock, regulates adipogenesis. Proc Natl Acad Sci U S A. 2005;102(34):12071-12076.

28. Grimaldi B, Bellet MM, Katada S, et al. PER2 controls lipid metabolism by direct regulation of PPAR $\gamma$. Cell Metab. 2010;12(5):509-520.

29. Duez H, Duhem C, Laitinen S, et al. Inhibition of adipocyte differentiation by RORalpha. FEBS Lett. 2009;583(12):2031-2036.

30. Wang J, Lazar MA. Bifunctional role of Rev-erbalpha in adipocyte differentiation. Mol Cell Biol. 2008;28(7):2213-2220.

31. Fontaine C, Dubois G, Duguay Y, et al. The orphan nuclear receptor Rev-Erbalpha is a peroxisome proliferator-activated receptor (PPAR) gamma target gene and promotes PPARgamma-induced adipocyte differentiation. J Biol Chem. 2003;278(39):37672-37680.

32. Meissburger B, Ukropec J, Roeder E, et al. Adipogenesis and insulin sensitivity in obesity are regulated by retinoid-related orphan receptor gamma. EMBO Mol Med. 2011;3(11):637-651.

33. Cristancho AG, Lazar MA. Forming functional fat: a growing understanding of adipocyte differentiation. Nat Rev Mol Cell Biol. 2011; 12(11):722-734.

34. Rosen $\mathrm{ED}$, Hsu $\mathrm{CH}$, Wang $\mathrm{X}$, et al. $\mathrm{C} / \mathrm{EBP} \alpha$ induces adipogenesis through PPAR $\gamma$ : a unified pathway. Genes Dev. 2002;16(1):22-26.

35. Guo B, Chatterjee S, Li L, et al. The clock gene, brain and muscle Arnt-like 1, regulates adipogenesis via Wnt signaling pathway. FASEB J. 2012;26(8):3453-3463.

36. Kohsaka A, Laposky AD, Ramsey KM, et al. High-fat diet disrupts behavioral and molecular circadian rhythms in mice. Cell Metab. 2007;6(5):414-421.

37. Yanagihara $\mathrm{H}$, Ando $\mathrm{H}$, Hayashi Y, Obi Y, Fujimura A. High-fat feeding exerts minimal effects on rhythmic mRNA expression of clock genes in mouse peripheral tissues. Chronobiol Int. 2006;23(5):905-914.

38. Turek FW, Joshu C, Kohsaka A, et al. Obesity and metabolic syndrome in circadian clock mutant mice. Science. 2005;308(5724):1043-1045.

39. Branecky KL, Niswender KD, Pendergast JS. Disruption of daily rhythms by high-fat diet is reversible. PLoS One. 2015;10(9):e0137970.

40. Barclay JL, Shostak A, Leliavski A, et al. High-fat diet-induced hyperinsulinemia and tissue-specific insulin resistance in Cry-deficient mice. Am J Physiol Endocrinol Metab. 2013;304(10):E1053-E1063.

41. Froy O. Metabolism and circadian rhythms - implications for obesity. Endocr Rev. 2010;31(1):1-24.

42. Shostak A, Husse J, Oster $\mathrm{H}$. Circadian regulation of adipose function. Adipocyte. 2013;2(4):201-206.

43. Bray MS, Young ME. Circadian rhythms in the development of obesity: potential role for the circadian clock within the adipocyte. Obes Rev. 2007;8(2):169-181.

44. Suzuki M, Shimomura Y, Satoh Y. Diurnal changes in lipolytic activity of isolated fat cells and their increased responsiveness to epinephrine and theophylline with meal feeding in rats. J Nutr Sci Vitaminol (Tokyo). 1983;29(4):399-411.

45. Dallmann R, Viola AU, Tarokh L, Cajochen C, Brown SA. The human circadian metabolome. Proc Natl Acad Sci U SA. 2012;109(7):2625-2629.

46. Fukagawa K, Gou HM, Wolf R, Tso P. Circadian rhythm of serum and lymph apolipoprotein AIV in ad libitum-fed and fasted rats. $A m$ J Physiol. 1994;267(5 Pt 2):R1385-R1390.

47. Escobar C, Díaz-Muñoz M, Encinas F, Aguilar-Roblero R. Persistence of metabolic rhythmicity during fasting and its entrainment by restricted feeding schedules in rats. Am J Physiol. 1998;274(5 Pt 2):R1309-R1316.

48. Oishi K, Shirai H, Ishida N. CLOCK is involved in the circadian transactivation of peroxisome-proliferator-activated receptor alpha (PPARalpha) in mice. Biochem J. 2005;386(Pt 3):575-581.

49. Inoue I, Shinoda Y, Ikeda M, et al. CLOCK/BMAL1 is involved in lipid metabolism via transactivation of the peroxisome proliferatoractivated receptor (PPAR) response element. $J$ Atheroscler Thromb. 2005;12(3):169-174.

50. Canaple L, Rambaud J, Dkhissi-Benyahya O, et al. Reciprocal regulation of brain and muscle Arnt-like protein 1 and peroxisome proliferator-activated receptor alpha defines a novel positive feedback loop in the rodent liver circadian clock. Mol Endocrinol. 2006; 20(8):1715-1727. 
51. Desvergne B, Wahli W. Peroxisome proliferator-activated receptors: nuclear control of metabolism. Endocr Rev. 1999;20(5):649-688.

52. Chappuis S, Ripperger JA, Schnell A, et al. Role of the circadian clock gene Per2 in adaptation to cold temperature. Mol Metab. 2013; 2(3):184-193.

53. Gerhart-Hines Z, Feng D, Emmett MJ, et al. The nuclear receptor Rev-erb $\alpha$ controls circadian thermogenic plasticity. Nature. 2013; 503(7476):410-413.

54. Vitaterna MH, King DP, Chang AM, et al. Mutagenesis and mapping of a mouse gene, Clock, essential for circadian behavior. Science. 1994;264(5159):719-725.

55. King DP, Zhao Y, Sangoram AM, et al. Positional cloning of the mouse circadian clock gene. Cell. 1997;89(4):641-653.

56. Pan X, Hussain MM. Clock is important for food and circadian regulation of macronutrient absorption in mice. J Lipid Res. 2009;50(9): $1800-1813$

57. Pan X, Zhang Y, Wang L, Hussain MM. Diurnal regulation of MTP and plasma triglyceride by CLOCK is mediated by SHP. Cell Metab. 2010;12(2):174-186.

58. Kennaway DJ, Voultsios A, Varcoe TJ, Moyer RW. Melatonin and activity rhythm responses to light pulses in mice with the clock mutation. Am J Physiol Regul Integr Comp Physiol. 2003;284(5):R1231-R1240.

59. Kennaway DJ, Owens JA, Voultsios A, Boden MJ, Varcoe TJ. Metabolic homeostasis in mice with disrupted clock gene expression in peripheral tissues. Am J Physiol Regul Integr Comp Physiol. 2007;293(4):R1528-R1537.

60. Kennaway DJ, Owens JA, Voultsios A, Wight N. Adipokines and adipocyte function in clock mutant mice that retain melatonin rhythmicity. Obesity (Silver Spring). 2012;20(2):295-305.

61. Kudo T, Tamagawa T, Kawashima M, Mito N, Shibata S. Attenuating effect of clock mutation on triglyceride contents in the ICR mouse liver under a high-fat diet. J Biol Rhythms. 2007;22(4):312-323.

62. Kennaway DJ, Varcoe TJ, Voultsios A, Boden MJ. Global loss of bmall expression alters adipose tissue hormones, gene expression and glucose metabolism. PLoS One. 2013;8(6):e65255.

63. Lamia KA, Storch KF, Weitz CJ. Physiological significance of a peripheral tissue circadian clock. Proc Natl Acad Sci U S A. 2008;105(39):15172-15177.

64. Shimba S, Ogawa T, Hitosugi S, et al. Deficient of a clock gene, brain and muscle Arnt-Like protein-1 (BMAL1), induces dyslipidemia and ectopic fat formation. PLoS One. 2011;6(9):e25231.

65. Hemmeryckx B, Himmelreich U, Hoylaerts MF, Lijnen HR. Impact of clock gene Bmall deficiency on nutritionally induced obesity in mice. Obesity (Silver Spring). 2011;19(3):659-661.

66. Kondratov RV, Kondratova AA, Gorbacheva VY, Vykhovanets OV, Antoch MP. Early aging and age-related pathologies in mice deficient in BMAL1, the core componentof the circadian clock. Genes Dev. 2006;20(14):1868-1873.

67. Bunger MK, Wilsbacher LD, Moran SM, et al. Mop3 is an essential component of the master circadian pacemaker in mammals. Cell. 2000;103(7):1009-1017.

68. Ikeda H, Yong Q, Kurose T, et al. Clock gene defect disrupts lightdependency of autonomic nerve activity. Biochem Biophys Res Commun. 2007;364(3):457-463.

69. Dallmann R, Touma C, Palme R, Albrecht U, Steinlechner S. Impaired daily glucocorticoid rhythm in Per1 (Brd) mice. J Comp Physiol A Neuroethol Sens Neural Behav Physiol. 2006;192(7):769-775.

70. Yang S, Liu A, Weidenhammer A, et al. The role of mPer2 clock gene in glucocorticoid and feeding rhythms. Endocrinology. 2009;150(5):2153-2160.

71. Costa MJ, So AY, Kaasik K, et al. Circadian rhythm gene period 3 is an inhibitor of the adipocyte cell fate. J Biol Chem. 2011;286(11): 9063-9070.

72. Dallmann R, Weaver DR. Altered body mass regulation in male mPeriod mutant mice on high-fat diet. Chronobiol Int. 2010;27(6):1317-1328.

73. Chomez P, Neveu I, Mansén A, et al. Increased cell death and delayed development in the cerebellum of mice lacking the rev-erbA(alpha) orphan receptor. Development. 2000;127(7):1489-1498.
74. Delezie J, Dumont S, Dardente H, et al. The nuclear receptor REV$\mathrm{ERB} \alpha$ is required for the daily balance of carbohydrate and lipid metabolism. FASEB J. 2012;26(8):3321-3335.

75. Solt LA, Wang Y, Banerjee S, et al. Regulation of circadian behaviour and metabolism by synthetic REV-ERB agonists. Nature. 2012;485(7396):62-68.

76. Lau P, Fitzsimmons RL, Raichur S, Wang SC, Lechtken A, Muscat GE. The orphan nuclear receptor, RORalpha, regulates gene expression that controls lipid metabolism: Staggerer (SG/SG) mice are resistant to diet-induced obesity. J Biol Chem. 2008;283(26):18411-18421.

77. Paschos GK, Ibrahim S, Song WL, et al. Obesity in mice with adipocyte-specific deletion of clock component Arntl. Nat Med. 2012; 18(12):1768-1777.

78. Lam TK, Pocai A, Gutierrez-Juarez R, et al. Hypothalamic sensing of circulating fatty acids is required for glucose homeostasis. Nat Med. 2005; 11(3):320-327.

79. Cintra DE, Ropelle ER, Moraes JC, et al. Unsaturated fatty acids revert diet-induced hypothalamic inflammation in obesity. PLoS One. 2012;7(1):e30571.

80. Martens K, Bottelbergs A, Baes M. Ectopic recombination in the central and peripheral nervous system by aP2/FABP4-Cre mice: implications for metabolism research. FEBS Lett. 2010;584(5):1054-1058.

81. Stephan FK, Zucker I. Circadian rhythms in drinking behavior and locomotor activity of rats are eliminated by hypothalamic lesions. Proc Natl Acad Sci U S A. 1972;69(6):1583-1586.

82. Kalsbeek A, Fliers E, Romijn JA, et al. The suprachiasmatic nucleus generates the diurnal changes in plasma leptin levels. Endocrinology. 2001;142(6):2677-2685.

83. Husse J, Eichele G, Oster H. Synchronization of the mammalian circadian timing system: light can control peripheral clocks independently of the SCN clock: alternate routes of entrainment optimize the alignment of the body's circadian clock network with external time. Bioessays. 2015;37(10):1119-1128.

84. Husse J, Zhou X, Shostak A, Oster H, Eichele G. Synaptotagmin10Cre, a driver to disrupt clock genes in the SCN. J Biol Rhythms. 2011;26(5):379-389.

85. Husse J, Leliavski A, Tsang AH, Oster H, Eichele G. The light-dark cycle controls peripheral rhythmicity in mice with a genetically ablated suprachiasmatic nucleus clock. FASEB J. 2014;28(11):4950-4960.

86. Barclay JL, Husse J, Bode B, et al. Circadian desynchrony promotes metabolic disruption in a mouse model of shiftwork. PLoS One. 2012;7(5):e37150.

87. Antunes LC, Levandovski R, Dantas G, Caumo W, Hidalgo MP. Obesity and shift work: chronobiological aspects. Nutr Res Rev. 2010; 23(1):155-168.

88. Hatori M, Vollmers C, Zarrinpar A, et al. Time-restricted feeding without reducing caloric intake prevents metabolic diseases in mice fed a high-fat diet. Cell Metab. 2012;15(6):848-860.

89. Damiola F, Le Minh N, Preitner N, Kornmann B, Fleury-Olela F, Schibler U. Restricted feeding uncouples circadian oscillators in peripheral tissues from the central pacemaker in the suprachiasmatic nucleus. Genes Dev. 2000;14(23):2950-2961.

90. Arble DM, Bass J, Laposky AD, Vitaterna MH, Turek FW. Circadian timing of food intake contributes to weight gain. Obesity (Silver Spring). 2009;17(11):2100-2102.

91. Bray MS, Ratcliffe WF, Grenett MH, Brewer RA, Gamble KL, Young ME. Quantitative analysis of light-phase restricted feeding reveals metabolic dyssynchrony in mice. Int J Obes (Lond). 2013;37(6):843-852.

92. Satoh Y, Kawai H, Kudo N, Kawashima Y, Mitsumoto A. Timerestricted feeding entrains daily rhythms of energy metabolism in mice. Am J Physiol Regul Integr Comp Physiol. 2006;290(5):R1276-R1283.

93. Arble DM, Vitaterna MH, Turek FW. Rhythmic leptin is required for weight gain from circadian desynchronized feeding in the mouse. PLoS One. 2011;6(9):e25079.

94. Chaix A, Zarrinpar A, Miu P, Panda S. Time-restricted feeding is a preventative and therapeutic intervention against diverse nutritional challenges. Cell Metab. 2014;20(6):991-1005. 
95. Guan Z, Vgontzas AN, Omori T, Peng X, Bixler EO, Fang J. Interleukin-6 levels fluctuate with the light-dark cycle in the brain and peripheral tissues in rats. Brain Behav Immun. 2005;19(6):526-529.

96. Arnoldussen IA, Kiliaan AJ, Gustafson DR. Obesity and dementia: adipokines interact with the brain. Eur Neuropsychopharmacol. 2014;24(12):1982-1999.

97. Bond DJ, Andreazza AC, Hughes J, et al. A longitudinal study of the relationships between mood symptoms, body mass index, and serum adipokines in bipolar disorder. J Clin Psychiatry. Epub 2016 Oct 25.

98. Parimisetty A, Dorsemans AC, Awada R, Ravanan P, Diotel N, Lefebvre d'Hellencourt C. Secret talk between adipose tissue and central nervous system via secreted factors-an emerging frontier in the neurodegenerative research. $J$ Neuroinflammation. 2016;13(1):67.

99. Kitagawa K, Miwa K, Okazaki S, Sakaguchi M, Mochizuki H. Serum high-molecular-weight adiponectin level and incident dementia in patients with vascular risk factors. Eur J Neurol. 2016;23(3): 641-647.

100. Schulz C, Paulus K, Lehnert H. Adipocyte-brain: crosstalk. Results Probl Cell Differ. 2010;52:189-201.

101. Vieira E, Ruano Eg, Figueroa AL, et al. Altered clock gene expression in obese visceral adipose tissue is associated with metabolic syndrome. PLoS One. 2014;9(11):e111678.

102. Gómez Abellán P, Gómez Santos C, Madrid JA, et al. Site-specific circadian expression of leptin and its receptor in human adipose tissue. Nutr Hosp. 2011;26(6):1394-1401.

103. Sinha MK, Ohannesian JP, Heiman ML, et al. Nocturnal rise of leptin in lean, obese, and non-insulin-dependent diabetes mellitus subjects. J Clin Invest. 1996;97(5):1344-1347.

104. Saad MF, Riad-Gabriel MG, Khan A, et al. Diurnal and ultradian rhythmicity of plasma leptin: effects of gender and adiposity. J Clin Endocrinol Metab. 1998;83(2):453-459.

105. Cuesta M, Clesse D, Pévet P, Challet E. From daily behavior to hormonal and neurotransmitters rhythms: comparison between diurnal and nocturnal rat species. Horm Behav. 2009;55(2):338-347.

106. Ahrén B. Diurnal variation in circulating leptin is dependent on gender, food intake and circulating insulin in mice. Acta Physiol Scand. 2000;169(4):325-331.

107. Gómez-Abellán P, Gómez-Santos C, Madrid JA, et al. Circadian expression of adiponectin and its receptors in human adipose tissue. Endocrinology. 2010;151(1):115-122.

108. Gavrila A, Peng CK, Chan JL, Mietus JE, Goldberger AL, Mantzoros CS. Diurnal and ultradian dynamics of serum adiponectin in healthy men: comparison with leptin, circulating soluble leptin receptor, and cortisol patterns. J Clin Endocrinol Metab. 2003;88(6): $2838-2843$.

109. Calvani M, Scarfone A, Granato L, et al. Restoration of adiponectin pulsatility in severely obese subjects after weight loss. Diabetes. 2004;53(4):939-947.

110. Rudic RD, McNamara P, Curtis AM, et al. BMAL1 and CLOCK, two essential components of the circadian clock, are involved in glucose homeostasis. PLoS Biol. 2004;2(11):e377.

111. Seo JB, Moon HM, Noh MJ, et al. Adipocyte determination- and differentiation-dependent factor $1 /$ sterol regulatory element-binding protein 1c regulates mouse adiponectin expression. $J$ Biol Chem. 2004;279(21):22108-22117.

112. Hashinaga T, Wada N, Otabe S, et al. Modulation by adiponectin of circadian clock rhythmicity in model mice for metabolic syndrome. Endocr J. 2013;60(4):483-492.

113. Berg AH, Combs TP, Scherer PE. ACRP30/adiponectin: an adipokine regulating glucose and lipid metabolism. Trends Endocrinol Metab. 2002;13(2):84-89.

114. Hayashida S, Kuramoto Y, Koyanagi S, et al. Proxisome proliferatoractivated receptor- $\alpha$ mediates high-fat, diet-enhanced daily oscillation of plasminogen activator inhibitor-1 activity in mice. Chronobiol Int. 2010;27(9-10):1735-1753.

115. Maemura K, de la Monte SM, Chin MT, et al. CLIF, a novel cycle-like factor, regulates the circadian oscillation of plasminogen activator inhibitor-1 gene expression. J Biol Chem. 2000;275(47):36847-36851.
116. Oishi K, Ohkura N, Wakabayashi M, et al. CLOCK is involved in obesity-induced disordered fibrinolysis in ob/ob mice by regulating PAI-1 gene expression. J Thromb Haemost. 2006;4(8):1774-1780.

117. Oishi K, Shirai H, Ishida N. Identification of the circadian clockregulated E-box element in the mouse plasminogen activator inhibitor-1 gene. J Thromb Haemost. 2007;5(2):428-431.

118. Singletary JH, Chan D, Samani NJ, Chong NW. The canonical E-box motif: a target for glucocorticoid action that drives rhythmic mouse Pai-1 transcription in vitro. Gene. 2008;420(1):42-47.

119. Nakahata Y, Sahar S, Astarita G, Kaluzova M, Sassone-Corsi P. Circadian control of the NAD+ salvage pathway by CLOCK-SIRT1. Science. 2009;324(5927):654-657.

120. Ramsey KM, Yoshino J, Brace CS, et al. Circadian clock feedback cycle through NAMPT-mediated NAD+ biosynthesis. Science. 2009;324(5927):651-654.

121. Wang J, Yin L, Lazar MA. The orphan nuclear receptor Rev-erb alpha regulates circadian expression of plasminogen activator inhibitor type 1. J Biol Chem. 2006;281(45):33842-33848.

122. Oliver P, Ribot J, Rodríguez AM, Sánchez J, Picó C, Palou A. Resistin as a putative modulator of insulin action in the daily feeding/fasting rhythm. Pflugers Arch. . 2006;452(3):260-267.

123. Andreotti F, Davies GJ, Hackett DR, et al. Major circadian fluctuations in fibrinolytic factors and possible relevance to time of onset of myocardial infarction, sudden cardiac death and stroke. Am J Cardiol. 1988;62(9):635-637.

124. Huber K, Rosc D, Resch I, et al. Circadian fluctuations of plasminogen activator inhibitor and tissue plasminogen activator levels in plasma of patients with unstable coronary artery disease and acute myocardial infarction. Thromb Haemost. 1988;60(3):372-376.

125. Cano P, Cardinali DP, Ríos-Lugo MJ, Fernández-Mateos MP, Reyes Toso CF, Esquifino AI. Effect of a high-fat diet on 24-hour pattern of circulating adipocytokines in rats. Obesity (Silver Spring). 2009;17(10):1866-1871.

126. Luna-Moreno D, Aguilar-Roblero R, Díaz-Muñoz M. Restricted feeding entrains rhythms of inflammation-related factors without promoting an acute-phase response. Chronobiol Int. 2009;26(7):1409-1429.

127. Sothern RB, Roitman-Johnson B, Kanabrocki EL, et al. Circadian characteristics of interleukin-6 in blood and urine of clinically healthy men. In Vivo. 1995;9(4):331-339.

128. Vgontzas AN, Bixler EO, Lin HM, Prolo P, Trakada G, Chrousos GP. IL-6 and its circadian secretion in humans. Neuroimmunomodulation. 2005;12(3):131-140.

129. Denis RG, Bing C, Naderali EK, Vernon RG, Williams G. Lactation modulates diurnal expression profiles of specific leptin receptor isoforms in the rat hypothalamus. J Endocrinol. 2003;178(2):225-232.

130. Stütz AM, Staszkiewicz J, Ptitsyn A, Argyropoulos G. Circadian expression of genes regulating food intake. Obesity (Silver Spring). 2007;15(3):607-615.

131. Li AJ, Wiater MF, Oostrom MT, et al. Leptin-sensitive neurons in the arcuate nuclei contribute to endogenous feeding rhythms. Am J Physiol Regul Integr Comp Physiol. 2012;302(11):R1313-R1326.

132. Couce ME, Burguera B, Parisi JE, Jensen MD, Lloyd RV. Localization of leptin receptor in the human brain. Neuroendocrinology. 1997; 66(3):145-150.

133. Guan XM, Hess JF, Yu H, Hey PJ, van der Ploeg LH. Differential expression of mRNA for leptin receptor isoforms in the rat brain. Mol Cell Endocrinol. 1997;133(1):1-7.

134. Burguera B, Couce ME, Long J, et al. The long form of the leptin receptor $(\mathrm{OB}-\mathrm{Rb})$ is widely expressed in the human brain. Neuroendocrinology. 2000;71(3):187-195.

135. Caron E, Sachot C, Prevot V, Bouret SG. Distribution of leptinsensitive cells in the postnatal and adult mouse brain. J Comp Neurol. 2010;518(4):459-476.

136. Gregor MF, Hotamisligil GS. Inflammatory mechanisms in obesity. Annu Rev Immunol. 2011;29:415-445.

137. Hotamisligil GS. Inflammation and metabolic disorders. Nature. 2006;444(7121):860-867. 
138. Lumeng CN, Bodzin JL, Saltiel AR. Obesity induces a phenotypic switch in adipose tissue macrophage polarization. $J$ Clin Invest. 2007;117(1):175-184.

139. Solinas G, Karin M. JNK1 and IKKbeta: molecular links between obesity and metabolic dysfunction. FASEB J. 2010;24(8):2596-2611.

140. Nakamura T, Furuhashi M, Li P, et al. Double-stranded RNA-dependent protein kinase links pathogen sensing with stress and metabolic homeostasis. Cell. 2010;140(3):338-348.

141. Schroder K, Zhou R, Tschopp J. The NLRP3 inflammasome: a sensor for metabolic danger? Science. 2010;327(5963):296-300.

142. Shi H, Kokoeva MV, Inouye K, Tzameli I, Yin H, Flier JS. TLR4 links innate immunity and fatty acid-induced insulin resistance. J Clin Invest. 2006;116(11):3015-3025.

143. Song MJ, Kim KH, Yoon JM, Kim JB. Activation of Toll-like receptor 4 is associated with insulin resistance in adipocytes. Biochem Biophy Res Commun. 2006;346(3):739-745.

144. Fonken LK, Lieberman RA, Weil ZM, Nelson RJ. Dim light at night exaggerates weight gain and inflammation associated with a high-fat diet in male mice. Endocrinology. 2013;154(10):3817-3825.
145. Fonken LK, Aubrecht TG, Meléndez-Fernández OH, Weil ZM, Nelson RJ. Dim light at night disrupts molecular circadian rhythms and increases body weight. J Biol Rhythms. 2013;28(4):262-271.

146. Chaix A, Zarrinpar A. The effects of time-restricted feeding on lipid metabolism and adiposity. Adipocyte. 2015;4(4):319-324.

147. Xu H, Li H, Woo SL, et al. Myeloid cell-specific disruption of Period1 and Period 2 exacerbates diet-induced inflammation and insulin resistance. J Biol Chem. 2014;289(23):16374-16388.

148. Nguyen KD, Fentress SJ, Qiu Y, Yun K, Cox JS, Chawla A. Circadian gene Bmal1 regulates diurnal oscillations of Ly6C(hi) inflammatory monocytes. Science. 2013;341(6153):1483-1488.

149. Johnston JD, Ordovás JM, Scheer FA, Turek FW. Circadian rhythms, metabolism, and chrononutrition in rodents and humans. Adv Nutr. 2016;7(2):399-406.

150. Johnston JD. Adipose circadian rhythms: translating cellular and animal studies to human physiology. Mol Cell Endocrinol. 2012;349(1): 45-50.

151. Blüher M. Adipokines - removing road blocks to obesity and diabetes therapy. Mol Metab. 2014;3(3):230-240.
ChronoPhysiology and Therapy

\section{Publish your work in this journal}

ChronoPhysiology and Therapy is an international, peer-reviewed open access journal focusing on research into the cyclic variations and rhythmicity in physiological processes in the body and the research and development and optimal timing of administration of therapeutic targets to achieve improved outcomes and quality of life for the patient. The

\section{Dovepress}

manuscript management system is completely online and includes a very quick and fair peer-review system. Visit http://www.dovepress.com/ testimonials.php to read real quotes from published authors. 